\title{
Differential expression in normal-adenoma-carcinoma sequence suggests complex molecular carcinogenesis in colon
}

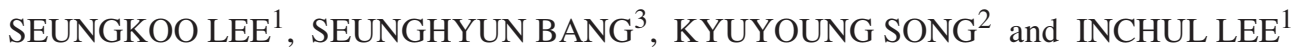 \\ Departments of ${ }^{1}$ Pathology, ${ }^{2}$ Biochemistry, and ${ }^{3}$ Molecular Biology, Asan Institute for Life Sciences, \\ Asan Medical Center, University of Ulsan College of Medicine, Seoul 138-736, Korea
}

Received March 24, 2006; Accepted June 27, 2006

\begin{abstract}
The majority of colon cancers develop from preexisting adenomas. We analyzed the expression profiles in the sequence of normal colon crypts, adenomas and earlystage carcinomas using microdissected cells from tubular adenomas with foci of malignant transformation. Differentially expressed genes were detected between normal-adenoma and adenoma-carcinoma, and were grouped according to the patterns of expression changes in the sequence. Down-regulated genes in the sequence included PLA2G2A, TSPAN1, PDCD4, FCGBP, AATK, EPLIN, FABP1, AGR2, MTUS1, TSC1, galectin 4 and MT1F. PLA2G2A has been shown to suppress colon tumorigenesis in mice, but the pathobiological role in humans has been controversial. Our data showed continuous down-regulation of PLA2G2A in the sequence supporting an implication in human colon cancer. Tumor suppressor and/ or proapoptotic activities have also been reported in other genes. Up-regulated genes included ribosomal proteins, IER3 and TPR. TGF- 32 and matrix metalloproteinase $23 \mathrm{~B}$ were up-regulated in carcinoma but not in adenoma, supporting the pathobiological roles in malignant transformation. Differentially expressed genes partly coincided with those in the adenoma-carcinoma sequence of the stomach, which was published previously, suggesting a partial overlap between the adenoma-carcinoma sequences of the colon and stomach.
\end{abstract}

\section{Introduction}

Colon cancers arise in pre-existing adenomas frequently, although alternative pathways are known to exist (1). Multiple genetic alterations have been implicated in the

Correspondence to: Dr Inchul Lee, Department of Pathology, Asan Medical Center, University of Ulsan College of Medicine, 388-1 Poongnap-Dong, Songpa-Gu, Seoul 138-736, Korea

E-mail: iclee@amc.seoul.kr

Key words: colon, adenoma-carcinoma sequence, expression profiling, microdissection, DNA microarray adenoma-carcinoma sequence (2). Many studies have suggested a role for uncharacterized genetic factors in predisposition to the majority of colon cancers (3-5). Thus, expression changes in the sequence might give us an insight into the molecular carcinogenesis. Nonetheless, surprisingly little expression profiling data of the adenoma/carcinoma sequence has been reported so far. The available data mostly report the differential expression between whole tissue samples of adenoma and carcinoma from multiple individuals (6-10). However, DNA microarray data using whole tissue samples of gastrointestinal tracts is particularly difficult to interpret because of considerable data noise from various inflammatory infiltration and reactive stromal changes (11). Furthermore, potential individual variations should be considered. To avoid those problems, it would be advantageous to investigate the sequential expression changes in a given adenoma with foci of malignant transformation and adjacent normal crypts using microdissection.

Formalin-fixation and paraffin-embedding is usually required for the delineation of subtle lesions such as malignant foci developing in adenoma. It also makes retrospective studies possible using paraffin blocks in pathology files. A problem of formalin-fixation is that it causes extensive base modification of nucleic acids (12), which makes it difficult to recover RNAs for the expression profiling. However, expression profiling of formalin-fixed tissue samples has been improved considerably $(13,14)$. Recently, we reported a reproducible procedure of RNA extraction and amplification which showed differential expression in the adenomacarcinoma sequence of the stomach (15).

The adenoma-carcinoma sequence may also be found in a group of stomach cancers $(16,17)$, although it does not seem to be as frequently shown as in colon. Gastric tubular adenomas almost always develop in the background of intestinal metaplasia and often show the adenoma-carcinoma sequence reminiscent of that in the colon (Lee I, unpublished data), suggesting that similar molecular sequences of carcinogenesis might be implicated in both type of cancers.

In this study, we analyzed the expression changes in the normal-adenoma-carcinoma sequence in the colon using microdissected cells from formalin-fixed, paraffin-embedded tissues. Differentially expressed genes were categorized according to the patterns of change in the sequence. They partly coincided with those published in the adenomacarcinoma sequence of the stomach, suggesting a partial 
overlap between the adenoma-carcinoma sequences in the colon and stomach. The pathobiological implications of $P L A 2 G 2 A$ and other differentially expressed genes in colon carcinogenesis are discussed.

\section{Materials and methods}

Tissue samples and microdissection. Two colon biopsies of tubular adenomas with focal malignant changes were selected from the surgical pathology file of Asan Medical Center, Seoul, Korea, following the guidelines of the Institutional Review Board. Polyps were incidentally detected in the sigmoid colon of 48- and 54-year old males who underwent colonoscopic check-up without clinical symptoms. They measured 3.0 and $1.4 \mathrm{~cm}$ in diameter, and were completely resected at the stalk.

Polyps were fixed immediately in $10 \%$ buffered-formalin and processed routinely. After the histopathological diagnosis, additional $6-\mu \mathrm{M}$ sections were taken from the paraffin blocks. For the sectioning and H\&E staining, all the solutions were freshly made using DEPC-treated water, and the slides and instruments were autoclaved. Normal crypts, adenoma and carcinoma cells were microdissected using an AutoPix laser capture microscope system (Arcturus, Mountain View, CA).

RNA extraction and amplification. Deparaffinized sections were removed from the slides by applying $200 \mu 1$ proteinase $\mathrm{K}$ buffer [2\% SDS, 10 mM Tris-HCl (pH 8.0), 0.1 mM EDTA]. Samples were transferred into a microcentrifuge tube and incubated at $70^{\circ} \mathrm{C}$ for $1 \mathrm{~h}$. Then, $3 \mu \mathrm{l}$ proteinase $\mathrm{K}(30 \mu \mathrm{g} / \mu \mathrm{l}$, Intron Biotechnology, Songnam, Korea) was added, and incubated again at $55^{\circ} \mathrm{C}$ for $1 \mathrm{~h}$. RNAs were extracted with TRIzol reagents (Invitrogen, Carlsbad, CA) as described previously (15).

First- and second-strand DNA synthesis was performed using T7dT primers and RNase H/T3N6 primers, as described previously (15). Then the double-stranded DNA was applied to PCR amplification using T7 promoter primers $(100 \mathrm{pM} / \mu 1$, 5'-CGGCCAGTGAATTGTAATACGACTCACTATAG GCG-3') and T3 promoter primers (100 pM/ $\mu 1,5^{\prime}-\mathrm{GCGCG}$ AAATTAACCCTCACTAAAGGGAGAGGG-3'). The PCR reaction was performed in a GeneAmp PCR 9600 system (PE Biosystems, Foster City, CA) for $1 \mathrm{~min}$ at $95^{\circ} \mathrm{C} ; 20$ cycles of $30 \mathrm{sec}$ at $95^{\circ} \mathrm{C}, 40 \mathrm{sec}$ at $65^{\circ} \mathrm{C}$ and $5 \mathrm{~min}$ at $68^{\circ} \mathrm{C}$; and $7 \mathrm{~min}$ at $68^{\circ} \mathrm{C}$. PCR products were purified using a MinElute ${ }^{\mathrm{TM}}$ PCR purification kit (Qiagen, Valencia, CA). In vitro transcription was performed using AmpliScribe ${ }^{\mathrm{TM}} \mathrm{T} 7$ or T3 high yield transcription kit (Epicenter, Madison, WI) at $37^{\circ} \mathrm{C}$ for $5 \mathrm{~h}$ in $40 \mu \mathrm{l}$ of reaction volume. Synthesized aRNA was purified using an RNeasy Mini kit (Qiagen).

cDNA microarray analysis. GenePlorer TwinChip Human-8K (Digital Genomics, Seoul, Korea) microarray chips were applied. The chips had two identical microarrays per slide, total gene spots of 8170 each. Probe labeling and hybridization were performed using the amine-modified random primer aminoallyl method as described previously $(15,18)$. Either adenoma or carcinoma was labeled with $\mathrm{Cy} 3$ and hybridized against the same normal control labeled with Cy5. Then, the hybridization was performed as described previously (15).

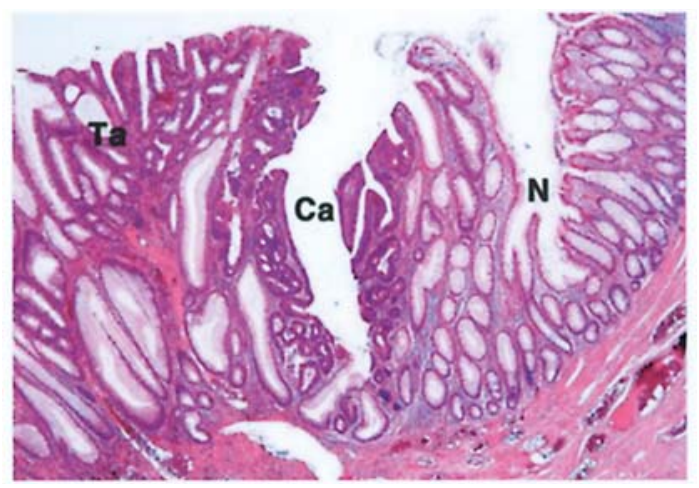

Figure 1. Histopathology of tubular adenoma (Ta) with focal malignant transformation $(\mathrm{Ca})$. The right hand side shows the stalk consisting of normal crypts $(\mathrm{N})$. (H\&E stain $\times 30)$.

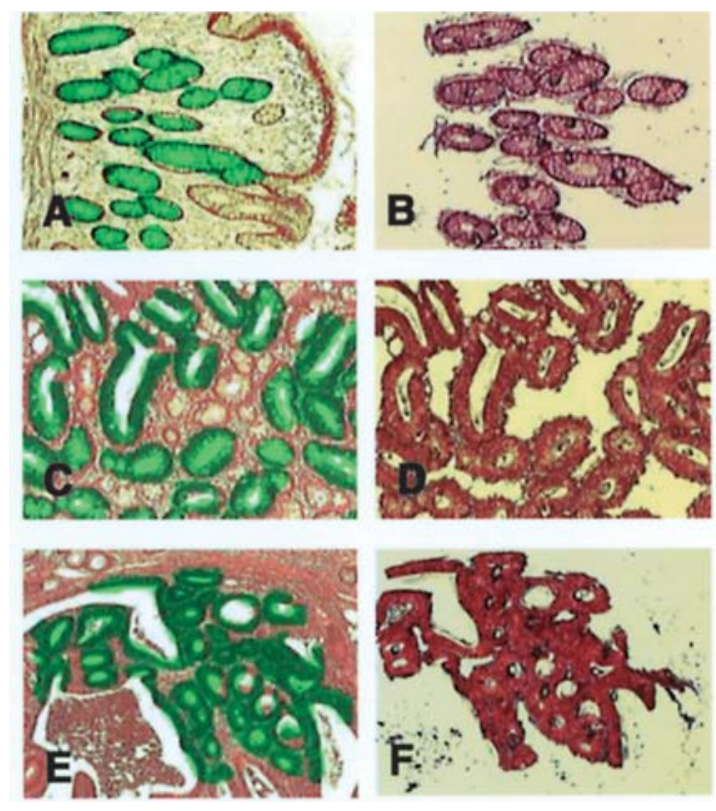

Figure 2. Crypts marked as green circles under the laser capture microscope before microdissection (left) and microdissected cells (right) of the normal gastric mucosa (A and B), adenoma ( $\mathrm{C}$ and $\mathrm{D})$, and carcinoma (E and $\mathrm{F})$. (H\&E stain x30).

Arrays were scanned with a GenePix 4000B scanner (Axon, Foster City, CA), and images were analyzed using the GeneSight program (BioDiscovery, Los Angeles, CA). Gene spots with threshold R-value $<2.0$ were omitted, and a total of 7087 normalized spots $(86.7 \%)$ were selected for analysis. Differentially expressed genes were analyzed using the Significance Analysis of Microarray (SAM) method, which provides the serial lists of both up-, and down-regulated genes at a given false-significance rate of choice (19).

\section{Results}

cDNA microarray analysis of normal-adenoma-carcinoma sequence. Tubular adenomas had foci of malignant transformation with early-stage stromal invasion (Fig. 1). They were completely resected at the stalk, which consisted of normal colon mucosa. Crypts from normal mucosa, adenoma, and carcinomas were microdissected without stromal or 
Table I. Up-regulated genes in colon polyps.

\begin{tabular}{|c|c|c|c|}
\hline Symbol & Title & Unigene ID & GenBank ID \\
\hline RPL23 & Ribosomal protein L23 & Hs.406300 & AI147195 \\
\hline PPAP2C & Phosphatidic acid phosphatase type $2 \mathrm{C}$ & Hs.24879 & AF047760 \\
\hline IER3 & Immediate early response 3 & Hs.76095 & AI185199 \\
\hline DDX21 & DEAD (Asp-Glu-Ala-Asp) box polypeptide 21 & Hs.169531 & U41387 \\
\hline RPL35 & Ribosomal protein L35 & Hs.182825 & AA305945 \\
\hline RECQL4 & RecQ protein-like 4 & Hs.31442 & AB006532 \\
\hline RPL13 & Ribosomal protein L13 & Hs.410817 & AI382216 \\
\hline GTF3A & General transcription factor IIIA & Hs.445977 & AI686944 \\
\hline AHCY & S-adenosylhomocysteine hydrolase & Hs.388004 & M61831 \\
\hline OLFM4 & Olfactomedin 4 & Hs.508113 & AI923293 \\
\hline TBC1D16 & TBC1 domain family, member 16 & Hs.458300 & AI683825 \\
\hline FLJ38753 & Hypothetical protein FLJ38753 & Hs.406913 & AI820608 \\
\hline TNNC2 & Troponin $\mathrm{C} 2$, fast & Hs.182421 & NM_003279 \\
\hline RPS12 & Ribosomal protein $\mathrm{S} 12$ & Hs.380956 & AA314429 \\
\hline PAIP1 & Poly(A) binding protein interacting protein 1 & Hs.374614 & AF013758 \\
\hline SORD & Sorbitol dehydrogenase & Hs.878 & U07361 \\
\hline GPX2 & Glutathione peroxidase 2 (gastrointestinal) & Hs.2704 & X68314 \\
\hline KIAA0582 & KIAA0582 & Hs.146007 & AI637917 \\
\hline DTX2 & Deltex homolog 2 (Drosophila) & Hs.89135 & AW001329 \\
\hline RPS7 & Ribosomal protein S7 & Hs.444012 & AA315981 \\
\hline CTSZ & Cathepsin Z & Hs.252549 & AI913006 \\
\hline TOP2A & Topoisomerase (DNA) II $\alpha 170 \mathrm{kDa}$ & Hs.156346 & NM_001067 \\
\hline TMEM9 & Transmembrane protein 9 & Hs.181444 & AI281733 \\
\hline SMARCC1 & SWI/SNF related, matrix associated, regulator of chromatin & Hs.162086 & AI333650 \\
\hline DACH1 & Dachshund homolog 1 (Drosophila) & Hs.63931 & AJ005670 \\
\hline TNFRSF12A & Tumor necrosis factor receptor superfamily, member 12A & Hs.355899 & AI827127 \\
\hline IFRD1 & Interferon-related developmental regulator 1 & Hs.7879 & Y10313 \\
\hline RPS14 & Ribosomal protein S14 & Hs.381126 & AI928982 \\
\hline MCLC & Mid-1-related chloride channel 1 & Hs.93121 & AI139458 \\
\hline HOXB2 & Homeo box B2 & Hs.290432 & X16665 \\
\hline DDAH2 & Dimethylarginine dirnethylaminohydrolase 2 & Hs.247362 & AI971320 \\
\hline GSTO1 & Glutathione S-transferase $\omega 1$ & Hs.11465 & AI752707 \\
\hline PAICS & Phosphoribosylaminoimidazole carboxylase & Hs.444439 & AI524157 \\
\hline GPC4 & Glypican 4 & Hs.58367 & AA887423 \\
\hline NHP2L1 & NHP2 non-histone chromosome protein 2-like 1 & Hs.182255 & AI338639 \\
\hline AUH & AU RNA binding protein/enoyl-Coenzyme A hydratase & Hs.81886 & X79888 \\
\hline KIAA1434 & Hypothetical protein KIAA1434 & Hs.145509 & AI187171 \\
\hline RPL9 & Ribosomal protein L9 & Hs.412370 & AI625598 \\
\hline TKT & Transketolase (Wernicke-Korsakoff syndrome) & Hs.89643 & AI378884 \\
\hline HHEX & Hematopoietically expressed homeobox & Hs.118651 & X67235 \\
\hline ZNF204 & Zinc finger protein 204 & Hs.8198 & AF033199 \\
\hline CAMLG & Calcium modulating ligand & Hs.13572 & AF068179 \\
\hline ZNF581 & Zinc finger protein 581 & Hs.82482 & AA280033 \\
\hline TPR & Translocated promoter region (to activated MET oncogene) & Hs.170472 & AA779660 \\
\hline C6orf11 & Chromosome 6 open reading frame 11 & Hs.436930 & AI745013 \\
\hline
\end{tabular}

inflammatory cells (Fig. 2). From 10000 microdissected cells, approximately 70-80 $\mu \mathrm{g}$ aRNA was obtained after in vitro transcription. The expression profiles were analyzed using cDNA microarrays. After normalization, 7087 gene spots
(86.7\%) were selected for analysis. The complete data set is publicly available in the NCBI Gene Expression Omnibus (http://www.ncbi.nlm.nih.gov/geo/) through the accession number GSE3880. 
Table II. Down-regulated genes in colon polyps.

\begin{tabular}{|c|c|c|c|}
\hline Symbol & Title & Unigene ID & GenBank ID \\
\hline PLA2G2A & Phospholipase A2, group IIA (platelets, synovial fluid) & Hs.76422 & H00742 \\
\hline SLC26A2 & Solute carrier family 26 (sulfate transporter), member 2 & Hs. 302738 & AA194161 \\
\hline MYLK & Myosin, light polypeptide kinase & Hs.386078 & AF069604 \\
\hline TSPAN1 & Tetraspan 1 & Hs.38972 & AF065388 \\
\hline PDCD4 & Programmed cell death 4 (neoplastic transformation inhibitor) & Hs. 257697 & N92498 \\
\hline PEX1 & Peroxisome biogenesis factor 1 & Hs. 164682 & AL046043 \\
\hline FCGBP & Fc fragment of IgG binding protein & Hs.111732 & D84239 \\
\hline AATK & Apoptosis-associated tyrosine kinase & Hs. 514575 & AB014541 \\
\hline CLDN7 & Claudin 7 & Hs. 513915 & AJ011497 \\
\hline SLC26A2 & Solute carrier family 26 (sulfate transporter), member 2 & Hs.302738 & U14528 \\
\hline HLA-DQA1 & Major histocompatibility complex, class II, DQ $\alpha 1$ & Hs.387679 & AI214199 \\
\hline C1orf34 & Chromosome 1 open reading frame 34 & Hs.112949 & AF007170 \\
\hline EPLIN & Epithelial protein lost in neoplasm $\beta$ & Hs.10706 & AL048161 \\
\hline APPL & Adaptor protein, PTB domain and leucine zipper motif 1 & Hs. 27413 & AA493310 \\
\hline SEMA6A & Sema domain, transmembrane domain and cytoplasmic domain & Hs.443012 & AB002438 \\
\hline SULT1A3 & Sulfotransferase family, cytosolic, 1A, phenol-preferring, member 3 & Hs. 460587 & L25275 \\
\hline FABP1 & Fatty acid binding protein 1 , liver & Hs.380135 & M10050 \\
\hline SLC26A3 & Solute carrier family 26 , member 3 & Hs. 1650 & L02785 \\
\hline NEK3 & NIMA (never in mitosis gene a)-related kinase 3 & Hs.2236 & Z29067 \\
\hline KIAA0703 & KIAA0703 gene product & Hs.6168 & AB014603 \\
\hline MATN2 & Matrilin 2 & Hs.153647 & AA953246 \\
\hline AGR2 & Anterior gradient 2 homolog (Xenopus laevis) & Hs. 226391 & AI800451 \\
\hline IMPA1 & Inositol(myo)-1(or 4)-monophosphatase 1 & Hs. 334022 & NM_005536 \\
\hline MTUS1 & Mitochondrial tumor suppressor 1 & Hs.7946 & AI028661 \\
\hline ITM2C & Integral membrane protein $2 \mathrm{C}$ & Hs.111577 & AA989167 \\
\hline MECP2 & Methyl CpG binding protein 2 (Rett syndrome) & Hs.3239 & NM_004992 \\
\hline PVRL3 & Poliovirus receptor-related 3 & Hs.436602 & AL050071 \\
\hline C9orf19 & Chromosome 9 open reading frame 19 & Hs.302766 & AI359275 \\
\hline PROC & Protein C (inactivator of coagulation factors Va and VIIIa) & Hs. 2351 & NM_000312 \\
\hline ENPP1 & Ectonucleotide pyrophosphatase/phosphodiesterase 1 & Hs. 213840 & M57736 \\
\hline IGLJ3 & Immunoglobulin $\lambda$ joining 3 & Hs.449601 & BF238115 \\
\hline IGJ & Immunoglobulin J polypeptide & Hs. 381568 & AA507911 \\
\hline TSC1 & Tuberous sclerosis 1 & Hs.69429 & AF013168 \\
\hline FXYD3 & FXYD domain containing ion transport regulator 3 & Hs. 301350 & AA826766 \\
\hline HDLBP & High density lipoprotein binding protein (vigilin) & Hs. 427152 & M64098 \\
\hline LGALS4 & Lectin, galactoside-binding, soluble, 4 (galectin 4) & Hs.5302 & AA130458 \\
\hline NUCB2 & Nucleobindin 2 & Hs.423095 & X76732 \\
\hline CD63 & CD63 antigen (melanoma 1 antigen) & Hs. 445570 & NM_001780 \\
\hline MGC31967 & Hypothetical protein MGC31967 & Hs.534579 & AI300939 \\
\hline DDX5 & DEAD (Asp-Glu-Ala-Asp) box polypeptide 5 & Hs. 279806 & X15729 \\
\hline AKAP9 & A kinase (PRKA) anchor protein (yotiao) 9 & Hs. 58103 & AB019691 \\
\hline ZYX & Zyxin & Hs.75873 & X94991 \\
\hline MUC1 & Mucin 1 , transmembrane & Hs.89603 & AI922289 \\
\hline DNCL12 & Dynein, cytoplasmic, light intermediate polypeptide 2 & Hs.369068 & AF035812 \\
\hline MT1F & Metallothionein $1 \mathrm{~F}$ (functional) & Hs .438737 & AI814448 \\
\hline
\end{tabular}

Differential expression in the sequence. Hybridization data of 4 normal-adenoma and normal-carcinoma sets were analyzed using the SAM method, respectively (19). At the expected false significance rate of $0.88 \%, 54$ up-regulated and 471 down-regulated genes were detected in combined adenoma/ carcinoma (Fig. 3). Up-regulated genes included ribosomal 
Table III. Genes up-regulated in cancer but not in adenoma.

\begin{tabular}{|c|c|c|c|}
\hline Symbol & Title & Unigene ID & GenBank ID \\
\hline TGFB2 & Transforming growth factor, $\beta 2$ & Hs.133379 & M19154 \\
\hline RERG & RAS-like, estrogen-regulated, growth inhibitor & Hs. 199487 & AI971219 \\
\hline RPESP & RPE-spondin & Hs.439040 & AA939100 \\
\hline DPP4 & Dipeptidylpeptidase 4 (CD26, adenosine deaminase complexing protein 2 ) & Hs.368912 & X60708 \\
\hline LRPPRC & Leucine-rich PPR-motif containing & Hs.368084 & AA663581 \\
\hline ISL1 & ISL1 transcription factor, LIM/homeodomain, (islet-1) & Hs.505 & U07559 \\
\hline ITGA4 & Integrin, $\alpha 4$ (antigen CD49D, $\alpha 4$ subunit ofVLA-4 receptor) & Hs.553495 & X16983 \\
\hline SLC35F5 & Solute carrier family 35 , member F5 & Hs.292509 & $\mathrm{N} 25427$ \\
\hline PDE4B & Phosphodiesterase 4B, cAMP-specific & Hs.198072 & L12686 \\
\hline MMP23B & Matrix metalloproteinase 23B & Hs.211819 & AB010961 \\
\hline ZNF217 & Zinc finger protein 217 & Hs. 155040 & AA460802 \\
\hline MPP6 & Membrane protein, palmitoylated 6 (MAGUK p55 subfamily member 6) & Hs.533355 & AI979249 \\
\hline MAP3K4 & Mitogen-activated protein kinase kinase kinase 4 & Hs.390428 & AI299943 \\
\hline CHML & Choroideremia-like (Rab escort protein 2) & Hs.170129 & N66913 \\
\hline FBX07 & F-box protein 7 & Hs.5912 & AI360050 \\
\hline
\end{tabular}

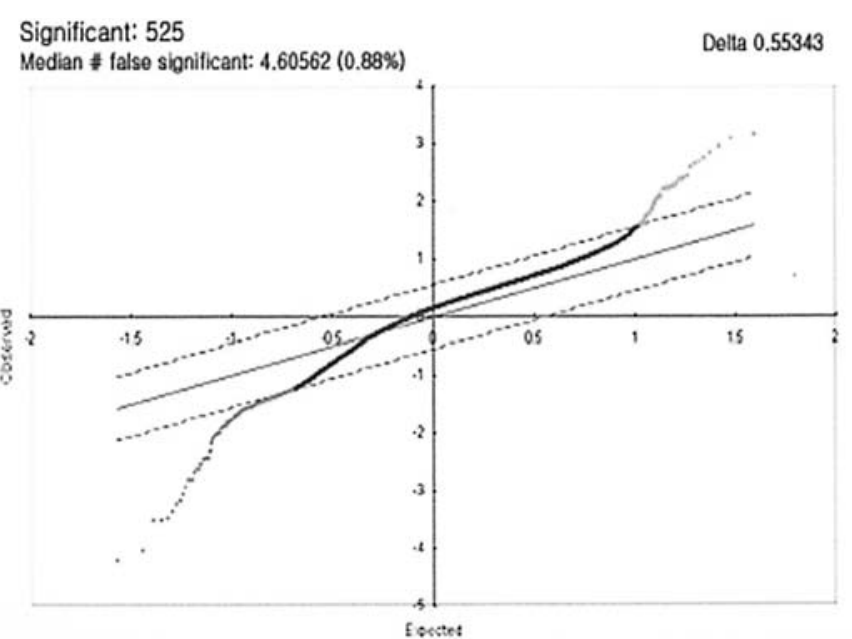

Figure 3. SAM analysis of colon polyps microdissected from formalin-fixed biopsies. At the expected false significance rate of $0.88 \%, 54$ up-regulated and 471 down-regulated genes were detected in colon polyps compared to normal mucosa crypts.

proteins, IER3, DDX21, RECQL4, AHCY, SORD, DDAH2, transketolase and TPR (Table I). TPR was reported to rearrange with MET oncogene upon chromosomal translocation in gastric cancers and precursor lesions (20).

Down-regulated genes included $P L A 2 G 2 A$, solute carrier proteins, TSPAN1, PDCD4, AATK, FCGBP, EPLIN, FABP1, AGR2, MTUS1, TSC1 and 2, galectin 4 and MT1F (Table II). $P L A 2 G 2 A$ has been shown to suppress APC-induced tumorigenesis in mice $(21,22)$. PDCD4 and $A A T K$ have been implicated in apoptosis $(23,24)$. PDCD4 has been reported to downregulate in lung, breast, colon, and prostate cancers (23), and also in stomach cancers (11). FCGBP is a mucin-like, non-Fc receptor protein, normally expressed in colon goblet cells (25). Mitochondrial tumor suppressor 1 (MTUS1) and metallo- thionein $1 \mathrm{~F}(M T 1 F)$ have been implicated in tumor suppressor activity and cancer growth inhibition $(26,27)$. TSC1 and 2 are tumor suppressor genes implicated in the tuberous sclerosis complex (28). Galectin 4 has been reported to down-regulate in colon cancers, suggesting an implication in early colorectal carcinogenesis (29). DDX5 is an RNA helicase which functions as a transcriptional repressor, being implicated in organ differentiation (30).

Pattern analysis of differentially expressed genes in the sequence. We then analyzed the step-wise changes in normaladenoma-carcinoma sequence. In comparison with adjacent normal crypts, tubular adenoma showed 422 up-, and 16 down-regulated genes at the expected false significance rate $0.66 \%$. In comparison with adenoma, carcinoma showed 20 up-, and 455 down-regulated genes at the expected false significance rate $0.16 \%$. Genes with differential expression were categorized into 9 groups according to the patterns in the normal-adenoma-carcinoma sequence as described in Materials and methods.

The group of genes that show significant up-regulation in carcinoma but not in adenoma might be implicated in the process of malignant transformation. This group included TGF- 32 and matrix metalloproteinase 23B (Table III). TGF- $\beta$ signaling controls diverse cellular responses and has been implicated in various cancers (31). Matrix metalloproteinases have been associated with cancer invasiveness (32).

Twenty-one genes showed continuous down-regulation in the normal-adenoma-carcinoma sequence, including PLA2G2A, FCGBP, SLC26A2, EPLIN, TSPAN1, PDCD4, PEX1, MTUS1, FABP1, DDX5, HLA-DQA1, AGR2, MT1F and galectin 4. Many genes have been reported to have tumor suppressor/ proapoptotic activities as described above. It was of interest that down-regulation of $H L A-D Q A 1$ has also been described by Nosho et al using fresh tissue samples of colon polyps without signal amplification (10). It has been implicated in 
Table IV. Overlapping genes between the adenoma/carcinoma sequences in the colon and stomach.

\begin{tabular}{ll}
\hline Symbol & Up-regulated genes \\
\hline RPL23 & Ribosomal protein L23 \\
IER3 & Immediate early response 3 \\
DDX21 & DEAD (Asp-Glu-Ala-Asp) box poly- \\
& peptide 21 \\
RECQL4 & RecQ protein-like 4 \\
AHCY & S-adenosylhomocysteine hydrolase \\
SORD & Sorbitol dehydrogenase \\
RPS7 & Ribosomal protein S7 \\
DDAH2 & Dimethylarginine dimethylaminohydrolase 2 \\
TKT & Transketolase (Wernicke-Korsakoff \\
& syndrome) \\
TPR & Translocated promoter region \\
RPS23 & Ribosomal protein S23 \\
EEF1B2 & Eukaryotic translation elongation factor 1
\end{tabular}

B 2

RPLP0

RPL37

RPLP1

RPS29

MRPL3

KPNB1

RPL10A

HMGB2

TRA1

CHD4

RPS27A

NCL

RPL11

ETS2

HNRPK

TPT1

TCF3

$\mathrm{MAGOH}$

SFRS1

MCM3

YWHAQ

HNRPU

SIVA

CXCL16

BARD1

POGZ

LBR

PRKAG1
Ribosomal protein, large, P0

Ribosomal protein L37

Ribosomal protein, large, P1

Ribosomal protein S29

Mitochondrial ribosomal protein L3

Karyopherin (importin) $\beta 1$

Ribosomal protein L10a

High-mobility group box 2

Tumor rejection antigen (gp96) 1

Chromodomain helicase DNA binding protein 4

Ribosomal protein S27a

Nucleolin

Ribosomal protein L11

v-ets erythroblastosis virus E26 oncogene

homolog 2

Heterogeneous nuclear ribonucleoprotein $\mathrm{K}$

Tumor protein, translationally-controlled 1

Transcription factor 3

Mago-nashi homolog, proliferationassociated

Splicing factor, arginine/serine-rich 1

MCM3 minichromosome maintenance deficient 3

Tyrosine 3-monooxygenase/tryptophan 5monooxygenase activation protein, $\theta$

polypeptide

Heterogeneous nuclear ribonucleoprotein U

CD27-binding (Siva) protein

Chemokine (C-X-C motif) ligand 16

BRCA1 associated RING domain 1

Pogo transposable element with ZNF domain

Lamin B receptor

Protein kinase, AMP-activated
Table IV. Continued.

\begin{tabular}{|c|c|}
\hline Symbol & Up-regulated genes \\
\hline ТMPO & Thymopoietin \\
\hline LIG1 & Ligase I, DNA, ATP-dependent \\
\hline BLVRB & $\begin{array}{l}\text { Diliverdin reductase B [flavin reductase } \\
(\mathrm{NADPH}) \text { ] }\end{array}$ \\
\hline GLB1 & Galactosidase, $\beta 1$ \\
\hline GBAS & Glioblastoma amplified sequence \\
\hline HSPCB & Heat shock $90 \mathrm{kDa}$ protein $1, \beta$ \\
\hline C14orf170 & Chromosome 14 open reading frame 170 \\
\hline PSMD11 & $\begin{array}{l}\text { Proteasome (prosome, macropain) } 26 \mathrm{~S} \\
\text { subunit }\end{array}$ \\
\hline ZDHHC3 & Zinc finger, DHHC domain containing 3 \\
\hline ATP6V1G1 & ATPase, $\mathrm{H}^{+}$transporting, lysosomal $13 \mathrm{kDa}$ \\
\hline ATP5L & ATP synthase, $\mathrm{H}^{+}$transporting \\
\hline FLJ14299 & Hypothetical protein FLJ14299 \\
\hline FBX07 & F-box only protein 7 \\
\hline Symbol & Down-regulated genes \\
\hline TSPAN1 & Tetraspan 1 \\
\hline FABP1 & Fatty acid binding protein 1 , liver \\
\hline AGR2 & Anterior gradient 2 homolog \\
\hline IGLJ3 & Immunoglobulin $\lambda$ joining 3 \\
\hline PIGR & Polymeric immunoglobulin receptor \\
\hline SLC12A2 & Solute carrier family 12 \\
\hline RPS4Y & Ribosomal protein S4, Y-linked \\
\hline
\end{tabular}

gastritis and gastric cancer (33), although the pathobiological role in colon carcinogenesis is not clear.

Overlapping in the sequences of the colon and stomach. We then compared the differentially expressed genes with those in the adenoma-carcinoma sequence of the stomach similarly studied in our previous study (the complete data set is publicly available at NCBI GEO, accession numbers GSM20670-5) (15). Numerous up-regulated genes overlapped in the colon and stomach sequence, including ribosomal proteins and $T P R$ (Table IV). Overlapping down-regulated genes included TSPAN1, FABP1 and AGR2, the pathobiological roles of which were not clear.

\section{Discussion}

We have shown the sequential expression change in the normal-adenoma-carcinoma sequence in the colon using microdissected cells from polyps with foci of malignant transformation. To our knowledge, this is the first report of the expression profiling in the colon adenoma-carcinoma sequence using microdissected cells. Differentially expressed genes were grouped according to the patterns of expression change, which might suggest pathobiological roles in the sequence. 
The expression profiling of microdissected cells has evident advantages in the analysis of subtle pathologic changes in continuity such as the adenoma-carcinoma sequence excluding the contamination of other cell types. On the other hand, a potential risk of the procedure-induced data noise should be weighed against the advantage. Nonetheless, several lines of evidence support the general applicability of our approach. Previously, we showed good correlation coefficients with fresh tissue counterparts using the same procedure (15). Also, the data recovery rate, $86.7 \%$ hybridization in all gene spots, was reasonably high. Furthermore, coinciding data was shown in other reports in which fresh samples were used without amplification. For instance, $H L A-D Q A l$ was also reported to be down-regulated in colon adenomas (10). Similarly, genes such as PDCD4, SEPPI, TSNAX and IGLJ3 were also downregulated in our previous expression profiling study of stomach cancer without amplification (11).

$P L A 2 G 2 A$ is one of the most extensively studied genes for tumorigenesis in the colon. It was first identified in mice as a chromosomal deletion mutant which modified the tumorigenesis caused by germ-line mutation of the Apc gene, Mom-1 (modifier of min-1) (34). Mom-1 was soon revealed to be $P L A 2 G 2 A$ (21), which played a central role in the cytokineinduced release of arachidonic acid (35). Later, PLA2G2A was shown to suppress APC-induced tumorigenesis in mice $(22,36)$. However, the pathobiological role in human colon cancer has been controversial as no coding sequence mutation was reported $(37,38)$. On the other hand, PLA2G2A has been shown to down-regulate in the majority of colon cancers $(39,40)$, suggesting its implication in human colon cancers. Our report of the continuous down-regulation of PLA2G2A in the adenoma-carcinoma sequence strongly supports its implication in the tumorigenesis and carcinogenesis of the colon. It is suggested that the transcriptional regulation of PLA2G2A might be of pathobiological significance in the adenoma-carcinoma sequence. PLA2G2A has been associated with prolonged survival in stomach cancers (41).

One of the advantages of microdissection-expression profiling is the sequential analysis at multiple transition points of disease progression. In this study, we analyzed 3 phases ( 2 transition points), resulting in grouping of differentially expressed genes into 9 groups according to the patterns of expression change. Such grouping based on sequential expression changes would facilitate the sorting of candidates for 'meaningful' genes in the functional genomics of cancer in vivo. More phases could be analyzed such as different grades of dysplasia, stromal invasion, or metastasis in various organs. This unique opportunity could also be applied to the analysis of pathogenetic steps and/or progression of other diseases in vivo.

The detection of multiple differentially expressed genes in the sequence suggests a complex molecular carcinogenesis in the colon. It is of interest that the sequential expression changes in the colon partly overlapped with those in the stomach (15). Our data suggests that the adenoma-carcinoma sequences in the colon and stomach might share certain common characteristics of carcinogenesis. Further analyses of differential expression in detailed pathological steps of carcinogenesis and cancer progression are required.

\section{Acknowledgements}

We appreciate Changhee Lee for technical assistance. This study was supported by a grant from the Korea Science \& Engineering Foundation (R01-2004-10670-0.

\section{References}

1. Jass JR, Whitehall VL, Young J and Leggett BA: Emerging concepts in colorectal neoplasia. Gastroenterology 123: 862-876, 2002.

2. Vogelstein B, Fearon ER, Hamilton SR, Kern SE, Preisinger AC, Leppert M, Nakamura Y, White R, Smits AM and Bos JL: Genetic alterations during colorectal-tumor development. N Engl J Med 319: 525-532, 1988.

3. Cannon-Albright LA, Skolnick MH, Bishop DT, Lee RG and Burt RW: Common inheritance of susceptibility to colonic adenomatous polyps and associated colorectal cancers. N Engl J Med 319: 533-537, 1988

4. Johns LE and Houlston RS: A systematic review and metaanalysis of familial colorectal cancer risk. Am J Gastroenterol 96: 2992-3003, 2001

5. Lichtenstein P, Holm NV, Verkasalo PK, Iliadou A, Kaprio J, Koskenvuo M, Pukkala E, Skytthe A and Hemminki K: Environmental and heritable factors in the causation of canceranalyses of cohorts of twins from Sweden, Denmark and Finland. N Engl J Med 343: 78-85, 2000.

6. Notterman DA, Alon U, Sierk AJ and Levine AJ: Transcriptional gene expression profiles of colorectal adenoma, adenocarcinoma and normal tissue examined by oligonucleotide arrays. Cancer Res 61: 3124-3130, 2001.

7. Agrawal D, Chen T, Irby R, Quackenbush J, Chambers AF, Szabo M, Cantor A, Coppola D and Yeatman TJ: Osteopontin identified as lead marker of colon cancer progression, using pooled sample expression profiling. J Natl Cancer Inst 94: 513-521, 2002.

8. Lin YM, Furukawa Y, Tsunoda T, Yue CT, Yang KC and Nakamura Y: Molecular diagnosis of colorectal tumors by expression profiles of 50 genes expressed differentially in adenomas and carcinomas. Oncogene 21: 4120-4128, 2002.

9. Williams NS, Gaynor RB, Scoggin S, Verma U, Gokaslan T, Simmang C, Fleming J, Tavana D, Frenkel E and Becerra C: Identification and validation of genes involved in the pathogenesis of colorectal cancer using cDNA microarrays and RNA interference. Clin Cancer Res 9: 931-946, 2003.

10. Nosho K, Yamamoto H, Adachi Y, Endo T, Hinoda Y and Imai K Gene expression profiling of colorectal adenomas and early invasive carcinomas by cDNA array analysis. Br J Cancer 92: 1193-1200, 2005.

11. Kim B, Bang S, Lee S, Kim S, Jung Y, Lee C, Choi K, Lee SG, Lee K, Lee Y, Kim SS, Yeom YI, Kim YS, Yoo HS, Song K and Lee I: Expression profiling and subtype-specific expression of stomach cancer. Cancer Res 63: 8248-8255, 2003.

12. Masuda N, Ohnishi T, Kawamoto S, Monden M and Okubo K: Analysis of chemical modification of RNA from formalin-fixed samples and optimization of molecular biology applications for such samples. Nucleic Acids Res 27: 4436-4443, 1999.

13. Bibikova M, Talantov D, Chudin E, Yeakley JM, Chen J, Doucet D, Wickham E, Atkins D, Barker D, Chee M, Wang Y and Fan JB: Quantitative gene expression profiling in formalinfixed, paraffin-embedded tissues using universal bead arrays. Am J Pathol 165: 1799-1807, 2004.

14. Paik S, Kim CY, Song YK and Kim WS: Technology insight: application of molecular techniques to formalin-fixed paraffinembedded tissues from breast cancer. Nat Clin Pract Oncol 2: 246-254, 2005.

15. Lee CH, Bang SH, Lee SK, Song KY and Lee I: Gene expression profiling reveals sequential change in gastric tubular adenoma and carcinoma in situ. World J Gastroenterol 11: 1937-1945, 2005.

16. Tahara E: Genetic pathways of two types of gastric cancer. IARC Sci Publ 157: 327-349, 2004.

17. Kase S, Osaki M, Honjo S, Adachi $\mathrm{H}$ and Ito $\mathrm{H}$ : Tubular adenoma and Intramucosal intestinal-type adenocarcinoma of the stomach: what are the pathobiological differences? Gastric Cancer 6: 71-79, 2003.

18. Xiang CC, Kozhich OA, Chen M, Inman JM, Phan QN, Chen Y and Brownstein MJ: Amine-modified random primers to label probes for DNA microarrays. Nat Biotechnol 20: 738-742, 2002. 
19. Tusher VG, Tibshirani R and Chu G: Significance analysis of microarrays applied to the ionizing radiation response. Proc Natl Acad Sci USA 98: 5116-5121, 2001.

20. Soman NR, Correa P, Ruiz BA and Wogan GN: The TPR-MET oncogenic rearrangement is present and expressed in human gastric carcinoma and precursor lesions. Proc Natl Acad Sci USA 88: 4892-4896, 1991.

21. MacPhee M, Chepenik KP, Liddell RA, Nelson KK, Siracusa LD and Buchberg AM: The secretory phospholipase A2 gene is a candidate for the Mom1 locus, a major modifier of ApcMininduced intestinal neoplasia. Cell 81: 957-966, 1995.

22. Cormier RT, Hong KH, Halberg RB, Hawkins TL, Richardson P, Mulherkar R, Dove WF and Lander ES: Secretory phospholipase Pla2g2a confers resistance to intestinal tumorigenesis. Nat Genet 17: 88-91, 1997.

23. Goke R, Barth P, Schmidt A, Samans B and Lankat-Buttgereit B: Programmed cell death protein 4 suppresses CDK1/cdc2 via induction of p21(Waf1/Cip1). Am J Physiol Cell Physiol 287: C1541-C1546, 2004.

24. Raghunath M, Patti R, Bannerman P, Lee CM, Baker S, Sutton LN, Phillips PC and Damodar Reddy C: A novel kinase, AATYK induces and promotes neuronal differentiation in a human neuroblastoma (SH-SY5Y) cell line. Brain Res Mol Brain Res 77: 151-162, 2000.

25. Kobayashi K, Ogata H, Morikawa M, Iijima S, Harada N, Yoshida T, Brown WR, Inoue N, Hamada Y, Ishii H, Watanabe M and Hibi T: Distribution and partial characterisation of $\operatorname{IgG~Fc}$ binding protein in various mucin producing cells and body fluids. Gut 51: 169-176, 2002.

26. Nouet S, Amzallag N, Li JM, Louis S, Seitz I, Cui TX, Alleaume AM, Di Benedetto M, Boden C, Masson M, Strosberg AD, Horiuchi M, Couraud PO and Nahmias C: Transinactivation of receptor tyrosine kinases by novel angiotensin II AT2 receptor-interacting protein, ATIP. J Biol Chem 279: 28989-28997, 2004.

27. Lu DD, Chen YC, Zhang XR, Cao XR, Jiang HY and Yao L: The relationship between metallothionein-1F (MT1F) gene and hepatocellular carcinoma. Yale J Biol Med 76: 55-62, 2003.

28. Astrinidis A and Henske EP: Tuberous sclerosis complex: linking growth and energy signaling pathways with human disease. Oncogene 24: 7475-7481, 2005.

29. Rechreche H, Mallo GV, Montalto G, Dagorn JC and Iovanna JL: Cloning and expression of the mRNA of human galectin-4, an S-type lectin down-regulated in colorectal cancer. Eur J Biochem 248: 225-230, 1997.

30. Abdelhaleem M: RNA helicases: regulators of differentiation. Clin Biochem 38: 499-503, 2005.
31. Narayan S, Thangasamy T and Balusu R: Transforming growth factor-beta receptor signaling in cancer. Front Biosci 10: 1135-1145, 2005.

32. Vihinen P, Ala-aho R and Kahari VM: Matrix metalloproteinases as therapeutic targets in cancer. Curr Cancer Drug Targets 5: 203-220, 2005

33. Azuma T, Ito S, Sato F, Yamazaki Y, Miyaji H, Ito Y, Suto H, Kuriyama M, Kato T and Kohli Y: The role of the HLA-DQA1 gene in resistance to atrophic gastritis and gastric adenocarcinoma induced by Helicobacter pylori infection. Cancer 82 : 1013-1018, 1998.

34. Dietrich WF, Lander ES, Smith JS, Moser AR, Gould KA, Luongo C, Borenstein N and Dove W: Genetic identification of Mom-1, a major modifier locus affecting Min-induced intestinal neoplasia in the mouse. Cell 75: 631-639, 1993.

35. Leslie CC: Properties and regulation of cytosolic phospholipase A2. J Biol Chem 272: 16709-16712, 1997.

36. Hong KH, Bonventre JC, O'Leary E, Bonventre JV and Lander ES: Deletion of cytosolic phospholipase A(2) suppresses Apc(Min)-induced tumorigenesis. Proc Natl Acad Sci USA 98: 3935-3939, 2001.

37. Riggins GJ, Markowitz S, Wilson JK, Vogelstein B and Kinzler KW: Absence of secretory phospholipase A2 gene alterations in human colorectal cancer. Cancer Res 55: 5184-5186, 1995.

38. Tomlinson IP, Beck NE, Neale K and Bodmer WF: Variants at the secretory phospholipase A2 (PLA2G2A) locus: analysis of associations with familial adenomatous polyposis and sporadic colorectal tumours. Ann Hum Genet 60: 369-376, 1996.

39. Dong M, Johnson M, Rezaie A, Ilsley JN, Nakanishi M, Sanders MM, Forouhar F, Levine J, Montrose DC, Giardina C and Rosenberg DW: Cytoplasmic phospholipase A2 levels correlate with apoptosis in human colon tumorigenesis. Clin Cancer Res 11: 2265-2271, 2005.

40. Edhemovic I, Snoj M, Kljun A and Golouh R: Immunohistochemical localization of group II phospholipase A2 in the tumours and mucosa of the colon and rectum. Eur J Surg Oncol 27: 545-548, 2001.

41. Leung SY, Chen X, Chu KM, Yuen ST, Mathy J, Ji J, Chan AS, Li R, Law S, Troyanskaya OG, Tu IP, Wong J, So S, Botstein D and Brown PO: Phospholipase A2 group IIA expression in gastric adenocarcinoma is associated with prolonged survival and less frequent metastasis. Proc Natl Acad Sci USA 99: 16203-16208, 2002. 